This item was submitted to Loughborough's Research Repository by the author.

Items in Figshare are protected by copyright, with all rights reserved, unless otherwise indicated.

\title{
Engineering education for mechatronics
}

PLEASE CITE THE PUBLISHED VERSION

https://doi.org/10.1109/41.481414

PUBLISHER

(c) IEEE

VERSION

AM (Accepted Manuscript)

LICENCE

CC BY-NC-ND 4.0

REPOSITORY RECORD

Acar, Memis, and Robert M. Parkin. 2019. "Engineering Education for Mechatronics". figshare. https://hdl.handle.net/2134/27168. 


\title{
Engineering Education for Mechatronics
}

\author{
Memiş Acar and Robert M. Parkin, Member, IEEE
}

\begin{abstract}
This paper defines mechatronics, explains mechatronics philosophy, and describes characteristics of mechatronics products and systems. It reviews some aspects of education and training for mechatronics and compares the two different approaches to engineering education: generalist engineering versus specialist engineering. It also examines the Japanese approach to product development strategies and mechatronics education and training. It also gives a bird's eye view of the mechatronics education in higher education institutions across the world with a specific reference to a typical mechatronics engineering degree program. Finally it concludes that, there will be an increasing need in the future for discipline-based mechatronics engineers.
\end{abstract}

\section{INTRODUCTION}

Conventional combinational design philosophies are in many cases, proving inadequate for the sophisticate products and speed of response demanded by today's markets. In many cases the Mechanical and the Electronic Design Departments of companies may even be in different cities or even countries. If, perchance, they are in the same building then they do not tend to communicate with each other with an inevitable effect on product design. Often the mechanical engineers design a machine; when finished they throw it over the wall to the electrical/electronic engineers to design and fit the control systems and they, in turn, throw it over the wall to the software engineers to write the control programs. Mechatronics is a trans-disciplinary approach, based on open communication systems and concurrent practices, to design better engineering products.

Mechatronic design philosophies and concurrent practices for achieving the physical embodiment of those designs are seen as an appropriate response to the challenge. The adoption of such philosophies requires engineers with a new range of skills and attitudes, sometimes tagged as Renaissance Men, with a concomitant stimulus to the providers of training and education. Universities and colleges have not been slow to react to this challenge. The Japanese university educational system tends to foster engineers with a transdisciplinary approach while in recent years, mechatronic engineering courses at undergraduate and postgraduate levels as well as vocational training courses, have been rapidly increasing in both European and the UK higher education institutions. More recent trends have seen a growing adoption of the mechatronic philosophy in the United States.

In all cases it is of paramount importance that the adoption of a mechatronic approach should have some added value. This may either be in terms of added functionality for the same price or a reduced price for similar functionality to that produced by a more conventional approach.
In many cases it is arguable that the adoption of mechatronic principles has produced an artefact which could not have been designed by any other means and is thus pushing the design process beyond the current horizons.

\section{MECHATRONICS PHILOSOPHY}

Mechatronics has been defined in several ways. In fact there are as many definitions as there are workers in the field. It is arguable that the semantics of the definition are unimportant. A common consensus would be to describe mechatronics as an integrative discipline utilizing the technologies of mechanics, electronics and information technology to provide enhanced products, processes and systems. It integrates the classical fields of mechanical engineering, electronic engineering and computer science/information technology at the design stage of a product or a system. Mechatronics is therefore not a new branch of engineering, but a newly developed concept that underlines the necessity for integration and intensive interaction between different branches of engineering.

The core disciplines of the mechatronics are undoubtedly set by the name, i.e., mechanics and electronics. This should not be taken literally as fixing the boundaries of mechatronics; mocha should be understood as the widest aspects of the physical embodiments of mechanical engineering, including optical elements, whilst tronics should be understood to embrace all aspects of microelectronics and information technology including control.

Most engineered products or processes have moving parts and require manipulation and control of their dynamic constructions to a required accuracy. This may involve the use of enabling technologies such as sensors, actuators, software, communications, optics, electronics, structural mechanics, and control engineering. A key factor in the mechatronics philosophy is the integration of microelectronics and information technology into mechanical systems, so as to obtain the best possible solution. Design of such products and processes, therefore, has to be the outcome of a multi- or transdisciplinary activity rather than an interdisciplinary one and must address other factors such as appropriateness. Hence mechatronics challenges traditional engineering thinking because the selection of means to the contemplated functional ends must involve crossing the boundaries between traditional engineering disciplines. Opponents of the Mechatronic Philosophy argue that it is "just systems engineering with a fancy new name". This can easily be refuted by considering examples where a mechatronic design has replaced products that were previously engineered using a systems approach with a resultant cost saving of significant proportions [1]. 
We may now refer to the definition of mechatronics by the EEC/IRDAC working party [2]: mechatronics is the synergetic combination of precision mechanical engineering, electronic control and systems thinking in the design of products and processes. There are, of course, many other versions of this definition but this one clearly underlines that mechatronics is focused on applications and design.

\section{MECHATRONICS PRODUCTS AND SYSTEMS}

A typical mechatronic system picks up signals, processes them, and, as an output, generates forces and motions. Mechanical systems are extended and integrated with sensors, microprocessors and controllers. The fact that such a system detects environmental or parametrical changes by sensors and, after suitably processing this information, reacts to them, makes it quite different from conventional machines and mechanical systems. For example, robots, digitally controlled engines, automated guided vehicles, electronic cameras, telefax machines, and photocopiers can be mentioned as typical mechatronics products.

The characteristics of mechatronic products and systems, according to Buur [3], are as follows: functional interaction between mechanical, electronic, and information technologies; spatial integration of subsystems in one physical unit; intelligence related to the control functions of the mechatronic system; flexibility, the ease with which mechatronic products can be modified to fit changing requirements and situations; multifunctionality attributed to the software defined functions of the microprocessor; invisible functions, performed by microelectronics and hard to see and understand by the customers; and technology dependence, closely interlinked with available manufacturing technologies.

Increased flexibility, versatility, intelligence level of products, safety, and reliability as well as lower energy consumption and cost are the gains achieved through applying mechatronics concepts to product design. These advantages translate into a product with more customer appeal, produced quickly at reduced cost and serving larger markets.

\section{GENERALISM VERSUS SPECIALISM}

King [4] argued in his inaugural lecture that "virtually all engineering was once the province of millwrights, whose craft had become wide reaching." He continued to say "the professions of the mechanical and civil engineers had not yet been defined or differentiated, the millwright was the closest approximation to both." Millwrights of the 18th century were responsible for developing the new machines on which the industrial revolution was founded.

Since then millwrights divided and fragmented into the myriad specializations that we recognize today. King argued that "the fragmentation of all these disciplines has serious consequences for design activities, where the creativity of the designer can be limited by the narrower perspective afforded by a high degree of specialism." He concluded that "in the closing decades of the 20th century there has been a move to return to more integrated production techniques and, with the development of microprocessors and microprocessor controlled systems and products, a need for integration in engineering design and education."

The arguments regarding generalization rage on. It is claimed that academics tend to favor narrow and deep specialization for its own sake. For many years companies existed with small enclaves of highly specialized engineers and discussions about products involving several technologies inevitably became protracted. The modem commercial climate is causing companies to rationalize their operations to adopt best practice or to go to the wall. Industry is now demanding engineers with both great depth and breadth (geniuses!). If generalism is taken too far then the engineers have covered a wide range of topics in insufficient depth to be of use. Thus the education and training of mechatronic engineers is very difficult. In any case it is not sufficient to educate over a wide range of topics and call the product a mechatronic engineer; the thorny problem of integration must be properly addressed. There is some evidence that many courses in mechatronics are simply a gluing together of mechanical and electronic components lacking a coherent integrative theme; in some cases departments are merely renaming their old systems engineering course.

Several course providers feel that a suitable mechatronics course should have four years of study (e.g., M.Eng. programs). Others accept the normal UK restriction of 3 years for a first degree and offer a mechatronics program. Opponents of this approach feel that it is not possible to give the required breadth and depth in three years and only offer mechatronics as a post graduate masters course and concentrate on giving more breadth and appreciation to single discipline graduates. The recent UK proposals for two-year degree courses are especially worrying for the providers of generalist courses.

The Massachusetts Institute of Technology convened a commission to study the productivity and performance of the USA industry [5]. The Commission also studied various sectors of higher education, including the engineering curriculum and made some recommendations. These include the following:

i) A new cadre of students and faculty characterized by the ability to operate effectively beyond the confines of a single discipline needs to be created.

ii) Emphasis on real-world, hands-on experience should be given and the students in the engineering schools should be exposed to real problems that go beyond the idealized abstractions that have dominated texts and homework since the 1950s.

iii) The importance of teamwork should be emphasized by introducing a practical team project that could substitute the undergraduate thesis.

The Commission has also recommended that the MIT School of Engineering should offer as an alternative path to the existing four-year curriculum a broader undergraduate program of instruction, followed by a professional degree program, without reducing the depth of the subjects studied. The professional undergraduate program would be discipline-based, but it would be broader than the current undergraduate programs. 
It was recommended that expanding breadth but preserving depth can only be achieved by increasing the number of years for a basic engineering education. The MIT Commission's recommendations reflect on the need for a new nucleus of engineers who have broader backgrounds but with specialist knowledge of a discipline and abilities to operate in a multidisciplinary project team. This proposition agrees with the concept of the mechatronic engineer, who may be seen as the inheritor of the spirit of the 18th Century millwrights, who were the generalist engineers of their time.

Both in Europe and the USA the current engineering education system is oriented toward producing specialist engineers. Although many engineering departments in the UK universities were conceived initially as departments of engineering, with only a very few notable exceptions they have developed into specialist departments, churning out specialist engineers. Even those which have maintained the broad ideals of general engineering promote final year specialization. There is some evidence, in the UK at least, that the move toward specialist departments is recognized as divisive, and there is a swing toward a return to the schoolbased structure which is in line with a closer working relationship of the professional engineering institutions.

\section{THE JAPANESE PARADIGM}

The success of Japanese industry in designing, developing, and marketing mechatronics products and systems may be attributed to the Japanese approach to product development strategies, their engineering education, and training system.

\section{A. Product Development Strategies}

Since mechatronic products and systems are characteristically different than those of traditional machines and electronic products, their development demands special methods and strategies, which Japanese companies seem to master far better than their European and American competitors.

Buur [3] argues that there are four particular patterns which characterize the product development practice of the most successful Japanese corporations: The Japanese react quickly to changes in competition, shorten the product cycle, emphasize the competitive product properties, and plan carefully for new markets.

Reduction in product lead times is difficult to achieve by the traditional compartmentalized sequential-product-development strategy, in which too much crucial information is lost at every transition from one department to another, resulting in loss of valuable time. To be internationally competitive, the product design and development activity must be performed concurrently, to ensure that a multidisciplinary design team considers all aspects of the product design and also sufficient attention is paid to market needs and manufacturing technologies [6]. Mechatronic design activity requires the operation and communication of engineering designers from different disciplines.

\section{B. Mechatronic Education and Training}

Japanese machinery companies are rapidly moving toward mechatronics and information technology, hence there is pressure on universities to produce the required graduates. Most of the engineering departments in Japanese universities tea6h elements of mechatronics within their courses, and conduct research in this field [7]. Since 1983, Toyohashi University runs a regular $\mathrm{ME}$ course in Mechatronic Engineering and Tohoku University changed the name of its Precision Engineering Department to Mechatronic and Precision Engineering. Postgraduate education is considered as both necessary and a good investment.

Japanese educationalists see the mechatronics engineer as a broader based mechanical engineer who has a good handson knowledge and ability in microprocessor hardware and software, electronics, actuators, and control. The Japanese national university system aids the formation of mechatronic engineers with good R\&D skills of benefit to industry [8]. Undergraduate programs are four years in length with the entire final year spent full time on a laboratory-based research project; the final year of the two year masters programs is also spent on such a project. The laboratory structure is typically centered around the professor, an associate, probably two research assistants, 2 or 3 Ph.D. students, 4 masters students, and 6 final year undergraduates. The students learn their research and development skills from the other members of the team in a manner not unlike apprenticeships. The proximity and concentration on a single subject promotes good team work and integration. There would appear to be very little cooperation outside of the laboratory personnel, thus it is not unusual for the lab to be involved in a multidisciplinary program without any in-depth skill in particular facets and so a willingness to transfer into other areas is a necessity. While many universities, notably Nagoya, Tokyo Institute of Technology, Tohoku, etc., are conducting good mechatronic research, there is evidence of duplication of effort and many similar, if not identical, projects may be found at other universities and the government laboratories such as MEL at Tsukuba.

The maturity of mechatronics in Japan is perhaps exemplified by the fact that research is subdividing and forming fragmentary specializations (e.g., optomechatronics) with in situations such as Gifu University having piezomechatronics, the Fukuda labs at Nagoya University having medimechatronics and micromechatronics, and Ibaraki University having biomechatronics [8].

Most Japanese companies assume that design is learned on the job, backed by in-house training. In addition to formal training the best way of creating engineers with general skills is to operate in-company education and job rotation schemes. The need for mechatronic engineers will depend on the company; some feel that generalist engineering training produces suitable engineers for mechatronics project teams, hence they rely upon generalist education and cooperation within the project team for the development of mechatronic products and processes. Others think that special programs for mechatronics are necessary as they have identified a requirement for Renaissance Man and feel that they can only be trained in house. 
TABLE I

MECHATRONICS IN EUROPEAN UNIVERSITIES

\begin{tabular}{|l|l|c|c|c|}
\hline Country & University & $\begin{array}{c}\text { Course } \\
\text { (PG/UG) }\end{array}$ & Research & Professor \\
\hline Austria & Johannes Kepler Univ. Linz & $\checkmark$ & & $\checkmark$ (New) \\
\hline Belgium & Katholieke Univ.of Leuven & $\checkmark$ & $\checkmark$ & \\
\hline Denmark & Technical Univ. of Denmark & $\checkmark$ & $\checkmark$ & \\
& & $\checkmark$ & $\checkmark$ & \\
\hline Finland & Tech. Univ. Helsinki & $\checkmark$ & $\checkmark$ & \\
& Tampere Univ. & $\checkmark$ & $\checkmark$ & \\
& Oulu Univ. & & $\checkmark$ & \\
\hline Netherlands & Twente Univ. & $\checkmark$ & $\checkmark$ & $\checkmark$ \\
\hline Switzerland & ETH Zurich & $\checkmark$ & $\checkmark$ & $\checkmark$ (New) \\
\hline Sweden & KTH Stockholm & & $\checkmark$ & $\checkmark$ (Unesco) \\
\hline Turkey & Bosphorous Univ. & & $\checkmark$ & \\
& METU & & & \\
\hline
\end{tabular}

\section{MECHATRONICS IN EUROPE}

Although the majority of the practicing European engineers have little or no knowledge of the mechatronics concept and philosophy, higher education institutions and some sectors of the industry in Europe seem to have embraced the subject of mechatronics more actively and there are encouraging signs that mechatronics is becoming recognized.

In Denmark, the establishment some ten years ago of the Danish Mechatronic Association has provided a firm foothold for the concept of mechatronics as an element of the engineering design process. Much of the focus for the Danish work in mechatronics lies in the Institute for Engineering Design (JED) and the Institute of Product Development (/PU) at the Technical University of Denmark (DTH) in Lyngby [9].

In 1985 a Mechatronics Group was formed in Finland with the intention of improving productivity in various sectors of industry. Furthermore the term mechatronics appeared in various E.U. research programs and several journals have sprung up to satisfy the need for focused organs of dissemination.

There is a healthy participation in research with notable centres at the University of Twente in the Netherlands and the University of Aachen in Germany and significant activity from the University of Coimbra (Portugal), the Scuola Superiore Santa Anna (Italy), Halmstad and Chalmers Universities in Sweden and the Middle Eastern Technical University (Turkey).

Table I shows those universities that are active in both research and the provision of courses at Undergraduate or Masters levels. Recent developments have seen the creation of Chairs in Mechatronics at Linz (Austria), KTH (Sweden), and Bosphorous (Turkey) Universities.

Activities in the Eastern sector have been gaining impetus as economies embrace the free market philosophy and look toward grass roots SME companies with transdisciplinary flexible engineering skills to replace inefficient, ailing, singleskill, large industrial units. University activities in research are largely leading the way with notable activity at Warsaw University (Poland) and Kaunas Technical University (Lithuania) while the most advanced are probably the Hungarian activities at the Technical University of Budapest, University of Miskolc, and Banki Donat College. There is considerable support in information dissemination from Mechatroninfo, the Hungarian Mechatronics Association.
TABLE II

POSTGRADUATE AND RESEARCH MECHATRONICS ACTIVITIES IN THE UK

\begin{tabular}{|l|c|c|c|}
\hline University & MSc Course & Research & Professor \\
\hline De Montfort Univ. & $\checkmark$ & $\checkmark$ & $\checkmark$ \\
\hline Dundee Univ. & $\checkmark$ & $\checkmark$ & $\checkmark$ \\
\hline Hull Univ. & $\checkmark$ & $\checkmark$ & \\
\hline King's College London & $\checkmark$ & $\checkmark$ & \\
\hline Lancaster Univ. & $\checkmark$ & $\checkmark$ & $\checkmark$ \\
\hline Loughborough Univ. of Techn. & $\checkmark$ & $\checkmark$ & $\checkmark$ \\
\hline Birmingham Univ_, & & $\checkmark$ & $\checkmark$ \\
\hline Cranfield Univ. & & $\checkmark$ & \\
\hline
\end{tabular}

\section{MECHATRONICS IN THE UK}

In recent years, mechatronics has gained an increasingly prominent place in the UK scene. This is clearly visible from the activities of a number of higher education institutions, IMechE and IEE, as well as publications and conferences.

\section{A. Research and PG Courses}

Several universities are active in research, but the major centers are undoubtedly those offering a Masters program to disseminate the research activities to industry in the shortest possible time. Table II shows the universities involved.

Lancaster University was one of the earliest involved while the M.Sc. at Dundee is notable in that it involves cooperation between Dundee University and Dundee Institute of Technology. The course at De Montfort has a considerable emphas.is on a multinational student body and European student exchange and emphasizes the business environment [10]. The University of Technology at Loughborough is one of the most advanced providers with a novel delivery suited to the attendance of part time industrially based students. This mode of provision has been used as the model for a proposed collaborative Integrated Graduate Development Scheme (IGDS) from Loughborough, Leicester, and De Montfort Universities. The course at the University of Hull follows a week-long-module pattern similar to the Loughborough course.

The Institutions of Mechanical Engineers (IMechE) and Electrical Engineers (IEE) have established the UK Mechatronics Forum. The primary aim of the Forum is to foster, promote, and advance the subject of mechatronics through meetings, visits, publications, conferences, and other activities.

\section{B. Mechatronics VG Education}

Lancaster University has established the first undergraduate degree course in mechatronics as a specialist option of their electronic and mechanical engineering courses. The University of Hull and Leeds University have followed soon after. Many others have appeared on the scene (Table III) and it should be noted that some providers are doing little more than renaming their systems engineering courses and paying scant attention to the fundamental issue of integration.

Several other universities and colleges have also embraced the subject to the extent of offering mechatronics courses at various levels. These include King's College London, 
TABLE III

MECHATRONICS UNDERGRADUATE COURSES IN THE UK

\begin{tabular}{|l|c|c|}
\hline University & BEng & MEng \\
\hline De Montfort Univ. & $\checkmark$ (BSc) & \\
\hline Univ. of Abertay Dundee & $\checkmark$ (BSc) & \\
\hline Glamorgan Univ. & $\checkmark$ & $\checkmark$ \\
\hline Hull Univ. & $\checkmark$ & $\checkmark$ \\
\hline King's College(London) & $\checkmark$ & $\checkmark$ \\
\hline Lancaster Univ. & $\checkmark$ & $\checkmark$ \\
\hline Leeds Univ. & $\checkmark$ & \\
\hline Manchester Metropolitan Univ. & $\checkmark$ & \\
\hline Middlesex Univ. & $\checkmark$ & $\checkmark$ \\
\hline StaffordshireUniv. & $\checkmark$ & \\
\hline Sussex Univ. & $\checkmark$ & \\
\hline Swansea Inst of HE & & \\
\hline
\end{tabular}

TABLE IV

MECHATRONIC ACTIVITIES IN THE REST OF THE WORLD

\begin{tabular}{|c|c|c|c|c|c|}
\hline Country & University & $\begin{array}{c}\text { Degree } \\
\text { Programme }\end{array}$ & $\begin{array}{l}\text { Course } \\
\text { (Module) }\end{array}$ & Research & Professor \\
\hline Australia & $\begin{array}{l}\text { Sydney NSW } \\
\text { South Queensland } \\
\text { NSW Kensington }\end{array}$ & $\checkmark$ & ," & $\begin{array}{l}\checkmark \\
\checkmark \\
\checkmark\end{array}$ & $\checkmark$ \\
\hline $\begin{array}{l}\text { Hong } \\
\text { Kong }\end{array}$ & $\begin{array}{l}\text { City Polytechnic of } \\
\text { Hong Kong }\end{array}$ & $\checkmark$ & & & \\
\hline USA & $\begin{array}{l}\text { Stanford } \\
\text { Rensselaer } \\
\text { Ohio State }\end{array}$ & & $\begin{array}{l}\checkmark \\
\checkmark \\
\checkmark\end{array}$ & $\begin{array}{l}\checkmark \\
\checkmark \\
\checkmark\end{array}$ & \\
\hline
\end{tabular}

Staffordshire University, Manchester Metropolitan University, Middlesex University, De Montfort University, University of Abertay Dundee, Glamorgan University, Swansea Institute of Higher Education, and Sussex University offering courses at degree level. Numerous universities and colleges of higher educations also offer courses at HND level. Furthermore, the Open University also offers a course entitled "Mechatronics: Designing Intelligent Machines."

\section{REST OF THE WORLD}

. Activity in the rest of the world is mainly to be found in Australia, Hong Kong and the USA. It should be noted that there is a tremendous growth in interest in the Pacific Rim but that it is usual for most of the educational provision, at this stage, to be made overseas (mainly Australia and the UK). Table IV shows the major centers.

A recent workshop on Mechatronics Education [11] had many, mainly North American institutions, claiming to teach mechatronics, but these were mainly offering a module (or unit) in microprocessor or microcontroller applications, usually at the senior year level. Among these institutions, Colorado State University, University of South Carolina, Rose-Hulman Institute of Technology (Indiana), Iowa State University, University of Delaware, Purdue University (Indiana), Georgia Institute of Technology, University of Washington, and Concordia University (Montreal) can be mentioned.

In some instances there were actually modules in mechatronics design, but no coherent total degree course, or certificate, in the subject other than those listed. This is sometimes due to the structure and rules of the institution (e.g., in some cases to offer a degree program it would be necessary to have a Department of Mechatronics). The examples of such
"Mechatronic System Design" or "Smart Product Design" can be seen at the Rensselaer Polytechnic Institute (NY) and Stanford University (CA). These courses are usually offered to senior or masters level students and require projects to be designed, built and tested and sometimes contested between groups.

Ohio State University offers an interdepartmental curriculum leading to "Certificate of Study" in "Electromechanical Engineering Design" in addition to the B.S. degree in either electrical or mechanical engineering. Students completing the designated courses qualify for the Certificate of Study.

An exciting development on the Australian scene is that, in addition to the four-year undergraduate degree in mechatronics which was initiated in 1990 by the Department of Mechanical and Mechatronics Engineering, the first permanent Chair in Mechatronics has been newly created at the University of Sydney.

City Polytechnic of Hong Kong has recently introduced a degree level mechatronics engineering program based on the present and future needs of the Hong Kong's industry [12]. This four-year B.Eng. course emphasizes the design of mechatronics products and processes. An important features of this course is that it has a significant proportion of time devoted to "active learning" through "doing" as opposed to "passive learning" through attending lectures.

\section{A TYPICAL MECHATRONICS DEGREE \\ CURRICULUM}

Most mechatronics undergraduate programs are largely based upon students taking existing mechanical and electronic engineering courses together with a specialized mechatronics option in' the final year, such as an industrially linked team project (13]. This approach could not adequately address the different educational objectives that the mechatronics demanded.

In October 1992, the University of Hull introduced undergraduate course in Mechatronics which has evolved with close collaboration of a group of leading UK companies is housed in the School of Engineering and Computing. The course has a novel structure that uses project-based teaching methods, combined with supporting lectures and tutorials, in the early years [14].

It is claimed that, by so structuring the course, students

i) develop simultaneously practical and theoretical understanding of underlying technical disciplines constituting mechatronics;

ii) develop interpersonal and communication skills and business awareness necessary to work in a multidisciplinary field; and

iii) develop and understanding of the process of engineering design.

The course philosophy is "to teach the underlying principles involved in designing mechatronics artifacts whilst also addressing the human and business skills necessary to translate a design into a manufactured product" [14]. It was claimed that appropriate project work would have the following benefits: 
TABLE V

MECHATRONICS B.E NG. COURSE AT THE UNIVERSITY OF HULL

\begin{tabular}{|c|c|c|c|}
\hline YEAR 1 & YEAR 2 & YEAR 3 & YEAR 4 \\
\hline Projects (50\%) & Projects (50\%) & & Individual project \\
\hline Lecture Topics (502fi): & Lecture Topics (50\%): & Lecture Topics: & Six to select from: \\
\hline Principles of Design & Business Finance & Software Engineering & Automated Assembly \\
\hline Computer Systems and & Transducer Technology & Manufacturing Systems & Systems \\
\hline Programming & Microprocessor Systems & Computer Aided Eng. & Design Analysis \\
\hline Materials & Project Management & Industrial and Production & Flexible Man. Systems \\
\hline Mechanical Systems & Control & Management & Ind. Control Systems \\
\hline Project Planning \& & Principles of & Automatic Control & Knowledge-based Eng. \\
\hline Management & Manufacturing & Digital Systems & Robotic Engineering \\
\hline Electronic Design & Design for Manufacture & Logic Programming & $\mathrm{CAD}$ \\
\hline Control & Information Systems & Techniques in Design for & Advanced Techniques in \\
\hline Drives and Sensors & & Manufacture & Control \\
\hline Report Writing & & & \\
\hline
\end{tabular}

i) address issues which are virtually impossible to convey in the lecture environment; for example the importance of team work, the need for a total quality approach, the compromise nature of engineering, the role of project planning and the necessity for good communication skills allow students to apply theory to real engineering problems and thus better appreciate the relevance of lecture courses;

ii) enable students to appreciate how specific topics and technologies can be integrated to form the basis of mechatronic product or systems;

iii) improve student motivation.

If the projects were appropriately chosen, with objectives well designed and structured and with regular assessment targets, then they could provide the integrating mechanism for teaching. Such work would also provide the essential experience in design issues, project planning, and management and communication skills.

From this central philosophy the structure of a four-year program, as detailed in Table $\mathrm{V}$, was devised.

The first year addresses the fundamentals of mechatronic product design via individual and group projects lasting 10 weeks and 15 weeks, respectively. Many of the thought modules are provided in the form of intensive modules in order to supply theoretical input to the project at the appropriate stages. Regular group discussions, progress reports and student presentations are an integral part of the course. The project work accounts for $50 \%$ of the end-of-year marking.

The second-year group project requires students not only to design and build a product to meet a specific need, but to consider also the manufacturing processes involved to make the product in volume. The project work accounts for $50 \%$ of the end-of-year marking. The basis of the project idea is supplied by industry.

The third year is aimed at strengthening and widening the academic base of students. The year is therefore lecture intensive, which expands students' knowledge, concepts, and theoretical grasp of key mechatronics disciplines.
The emphasis in the final year is to reinforce the systembased approach to modern-day engineering practice. Students specialize in mechatronic topics of their choice. Lecture courses are chosen from either the Departments of Computer Science, Engineering Design and Manufacture or Electronic Engineering. Students are also required to undertake a substantial individual project that may either be research based or a mechatronic product/process design problem.

\section{CONCLUSION}

The mechatronic engineer of the future is the rare individual who is able to work across the boundaries of constituent disciplines to identify and use the right combination of technologies which will provide the optimum solution to the problem in hand. He/she should also be a good communicator who is able work in and lead a design team which may consist of specialist engineers as well as generalists.

If the West is to survive the fierce international competition in design and development of mechatronic products, significant attention has to be given to mechatronics education and raising the awareness of mechatronic approach to design of products and processes. The initial urgent task of the engineering educationalist should be to make engineers at all levels aware of the mechatronics concepts applied to product design and its significance to industry. The importance of mechatronics design must be stressed at all levels in the teaching of engineering, particularly in mechanical engineering.

The educational systems in the West will have to move or return to discipline-based generalist courses at undergraduate level with the ability to gain further specialism at either postgraduate level or by in-house training in industry. This may require an extension of the courses from three-year to four-year or from four-year to five-year, as proposed by the MIT Commission. It is perhaps not possible nor desirable to convert every mechanical engineer into a mechatronic engineer, but the point is that traditional engineers must learn to appreciate the other specialist disciplines and hence to communicate with them at the product design stage. If mechatronics education is to succeed in playing a significant 
role in the formation of the engineers of the future and in the development of engineering education then it is essential that industry plays its part in that development. Indeed it is important that industry adopts a leading role in the setting up and development of courses at universities, provides realworld design projects for students, and accepts that in-house training is worthwhile for engineers employed.

\section{REFERENCES}

[1] R. M. Parkin, "What is this thing called mechatronics?, " Inaugural Professorial Lecture, University of Technology, Loughborough, May 4, 1994.

[2] J. A. Rietdijk, "Ten propositions on mechatronics,"in Mechatronics in Products and Manufacturing Conf, Lancaster University, UK, Sept. 11-13, 198

[3] J. Buur, "Mechatronics design in Japan," Institute for Engineering Design, Technical University of Denmark, 1989.

[4] T. G. King, "Millwrights to mechatronics: The merits of multidisciplinary engineering," Inaugural Professorial Lecture, University of Birmingham, Mar. 17, 19.94.

[5] M. L. Dertouzos, R. K. Lester, and R. M. Solow, Made in America-Regaining the Productive Edge. New York: Harper Perennial, 1989.

[6] D. Bayliss, R. Akueson, J. Knight, and R. M. Parkin, "Implementing concurrent engineering using intelligent systems," in Proc. CEEDA '94 2nd Int. Conf Concurrent Eng. \& Electron. Design Automat., Bourn- mouth, Apr. 7-8, 1994, pp. 75-80.

[7] J. R. Hewit, M. R. Jackson, and M. E. Preston, "Mechatronics in Japan and Europe," Department of Mechanical Engineering, Loughborough University of Technology, UK, 1989.

[8] R. M. Parkin, "Report on visit to Japan, May-June 1994," Communication to the Royal Society, Department of Mechanical Engineering, University of Technology, Loughborough, p. 31, 1994.

[9] D. Bradley, "Mechatronics in Denmark", Mechatronics Forum Newsletter, Spring/Summer, no. 3, p. 3, 1992.

[10] R. M. Parkin, "Mechatronics at De Montfort university," in Trans. Hungarian Sci. Assoc. Mechanical Eng. (SAME), Hidro-Pneu 93/9, pp. 38-42, 1993.

[11] Proc. Workshop Mechatronics Education, Stanford University, USA, Jul. 21-23, 1994, p. 116.

[12] P. K. Venuvinod and K. P. Rao, "A mechatronic engineering degree course to meet the needs of Hong Kong," in Proc. Mechatronics, Machine Vision in Practice Conf, Toowoomba, Australia, Sept. 13-15, 1994, pp. 52-57.
[13] A. P. Dorey and D. A. Bradley, "Integrating electronics with mechanical engineering," in Sixth Conf - Teaching of Electron. Eng. in Degree Courses, University of Hull, Mar. 28-30, 1988, pp. 28.128.8 .

[14] G. G. Rogers, D. G. Whitehead, and S. R. Owen, "A four year B.Eng. (Hons.) mechatronic degree programme," in MechatronicsThe Basis for new Industrial Development. Southampton: Computational Mechanics Publications, 1994, pp. 819-823.

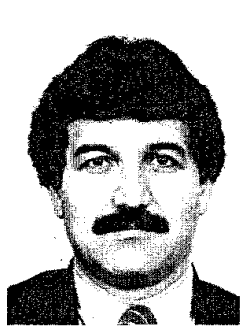

Memi§ Acar graduated, in 1974, from the Department of Mechanical Engineering of the Middle East Technical University, Ankara, Turkey, where he was later appointed as an Assistant Lecturer before winning a Turkish Government Grant to undertake research in the UK. This grant enabled him in 1979 to receive the M.Sc. degree from the University of Manchester Institute of Science and Technology and in 1984 to receive the Ph.D. degree from Loughborough University of Technology.

He was then employed as Research Assistant and subsequently as a Research Fellow in the Department of Mechanical Engineering at Loughborough. In October 1986 he was appointed as a Lecturer within the same department. He is currently a Senior Lecturer.

Dr Acar is a member of ASME, a Fellow of the Institution of the Mechanical Engineers (FIMechE) as a chartered engineer (CEng), and a Fellow of the Textile Institute (FTI) as a chartered textile technologist (CText). In 1992, he organized, with the support of the NATO Scientific Affairs Division, a two-week NATO Advanced Study .Institute meeting entitled "Advancements and Applications of Mechatronics Design in Textile Engineering." In 1994, he acted as the conference organizer on behalf of the UK Mechatronics Forum for the Joint Hungarian/British Mechatronics Conference. He organized a special session on Mechatronics Education and Training for the ICRAM'95 Mechatronics Conference, held in August 1995. He currently represents the Institution of Mechanical Engineers on the U.K. Mechatronics Forum Committee.

Robert M. Parkin (M'94), for a photograph and biography, see p. 29 of this issue of this TRANSACTIONS. 